\title{
Attempt to Explore the Binding Mechanism of IL-1 $\beta$ Inhibitors via Molecular Docking Studies
}

Sobia Ahsan Halim ${ }^{1,2 *}$ and Muhammad Jawad ${ }^{2}$

${ }^{1}$ Department of Biochemistry, Kinnaird College for Women, 93-Jail Road, Lahore, Pakistan

${ }^{2}$ National Centre of Excellence in Molecular Biology, University of the Punjab, Lahore, Pakistan

\begin{abstract}
$\mathrm{IL}-1 \beta$ is an important cytokine involved in several immune responses. IL-1 $1 \beta$ exerts its effect by binding with its receptor called IL-1R1 and leading to a series of intra-cellular signalling. The over-expression of IL-1 $\beta$ leads to immunological complications including arthritis and auto-immune disorders. Currently there are several drugs in the market to cure the inflammation either by inhibiting the production of IL-1 $\beta$ or affecting its signal cascade. The hindrance in the interaction between IL-1 $\beta$ interaction and its receptor can stop its function hence hope to cure inflammatory diseases. This study presents a docking analysis of five commercially available drugs at the IL-1 $\beta / \mathrm{IL}-1 \mathrm{R} 1$ protein interface. This study would give an insight for designing the drugs, capable to block the direct interaction of IL-1 $\beta$ with its receptor ultimately leading to some more consistent cure for inflammatory diseases.
\end{abstract}

\section{Keywords: IL-1 $\beta$; IL-1R1; Docking}

Abbreviations: IL-1 $\beta$ : Interleukin-1 Beta; IL-1R1: Interleukin-1 Receptor I; MOE: Molecular Operating Environment

\section{Introduction}

Interleukine-1 is one of the most important families of cytokines consisting of 11 members of cytokines [1]. This family has been known as regulators of immunity [2], which is primarily associated with release of IL-2, maturation and proliferation of B-cell, T lymphocytes and stimulation of thymocyte proliferation by activating fibroblast growth factor [3]. This family is involved in pro-inflammatory responses and is being called as endogenous pyrogens [4]. It causes a variety of cellular activities, including cell proliferation, differentiation, and apoptosis [2,5-8] thus leads to several autoimmune, auto-inflammatory, infectious and degenerative diseases. The members of this family bind to a class of receptor known as IL-1R. There are two types of receptor IL-1RI and IL-1RII. IL- $1 \alpha$ and IL- $1 \beta$ are the important members of IL- 1 cytokine family with a size of $17.3 \mathrm{kDa}$. They have common biological properties but they vary in their immune response [9]. Both IL-1 $\alpha$ and $\beta$ binds to a same receptor IL-1RI to exert their function. The protein IL-1ra is a natural antagonist, which binds to IL-1RI leads to the blockage of interaction of IL-1 $\beta$ with its receptor IL-1RI [10-12].

IL-1 $\beta$ has a prime importance due to its crucial role in different immune responses in the body. The prominent role of IL- $1 \beta$ is in the form of pain and inflammation that are resultant of signal cascade activated by the interaction of IL- $1 \beta$ and IL-1RI $[13,14]$. The importance of IL$1 \beta$ over IL- $1 \alpha$ can be estimated through two different studies. Firstly the elevated secretion of IL- $1 \beta$ causes auto-inflammatory diseases $[1,5]$ but elevated secretion of IL- $1 \alpha$ does not show any such response. In another research the distinction can be found in their response to cancer, a comparison study done by Krelin et al. [15], showed that mice deficit in IL- $1 \beta$ developed less tumours than mice deficit in IL$1 \alpha$, which means elevated levels of IL- $1 \beta$ may be responsible for cancer rather than IL-1 $\alpha$. IL-1 $\beta$ is also responsible for tumour angiogenesis and metastatic spread of tumours [16]. Thus the IL-1 family presents a favourable inflammatory micro-environment for proliferating cancer tumours [17]. The normal production of IL-1 $\beta$ also has a vital role in homeostatic functions (feeding, sleep and temperature) in normal organisms $[10,11]$. But its overproduction is responsible for pathophysiological abnormalities such as rheumatoid arthritis, inflammatory bowel disease, osteoarthritis, vascular disease, multiple sclerosis, neuropathic pain, and Alzheimer's disease [11,12,18].
Obesity is a major problem in the world; IL-1 $\alpha$ and IL- $1 \beta$ is playing an important role in causing obesity [19], and involved in atherosclerosis [20], while atheroma is associated with IL-1 $\beta$. Dan et al. [21] studied the impact of IL-1 $\beta$ on insulin signalling in human primary adipocytes. The study showed that IL- $1 \beta$ is involved in stimulating the effect of macrophages on insulin and pro-inflammatory response in human adipocytes and it was suggested that by blocking IL- $1 \beta$ could help in curing the obesity problem. The inhibition of IL-1 $\beta$ function also reduces the hyperglycemia and tissue inflammation in obese mice and diabetic rats [22-25]. Dysregulated IL-1 $\beta$ activity has become the target of choice for the treatment of inflammatory diseases. Hence the importance of therapeutic development against IL- $1 \beta$ cannot be denied. The market for IL-1 blocking agents is highly competitive, and multiple candidates are being developed for a range of therapeutic indications. Currently available drugs either affect the IL- $1 \beta$ production or its signalling pathway. For example Canakinumabm, Xoma-052 and LY2189102 are monoclonal antibodies that blocks IL-1 $\beta$. Similarly K-832 and CYT- $013-i L 1 b Q b$ are IL- $1 \beta$ secretion inhibitor and IL- $1 \beta$ vaccine, respectively [26]. The use of monoclonal antibodies as therapeutics has a promising solution for diluting the effect of IL-1b [27]. However, therapeutic antibodies have several disadvantages including high cost and nonexistence of oral bioavailability. A small molecule inhibitor of the IL-1 $\beta /$ IL- 1 R1 interaction could offer a significant development in immuno-suppressive therapy. Until now, small molecule inhibitors of IL-1 $\beta$ have been difficult to identify [28]. In contrast, computational drug design tactics can be effectively carried out resulting in lower cost and less time.

Stemming from our interest to search new IL-1 $\beta$ inhibitors $[29,30]$ this study was conducted to explore the binding mechanism of potent anti-inflammatory drugs via an in silico strategy. Molecular docking simulations plays a crucial role in the prediction of protein-ligand

*Corresponding author: Sobia Ahsan Halim, Department of Biochemistry Kinnaird College for Women, 93-Jail Road, Lahore, Pakistan, Tel: +92 42 99203781-84 extn. 226; E-mail: sobia.ahsan@kinnaird.edu.pk; sobiahal@gmail.com

Received September 29, 2015; Accepted October 12, 2015; Published October 15,2015

Citation: Halim SA, Jawad M (2015) Attempt to Explore the Binding Mechanism of IL-1 Inhibitors via Molecular Docking Studies. Med chem 5: 452-457. doi:10.4172/2161-0444.1000300

Copyright: $\odot 2015$ Halim SA, et al. This is an open-access article distributed under the terms of the Creative Commons Attribution License, which permits unrestricted use, distribution, and reproduction in any medium, provided the original author and source are credited. 
interactions; hence the purpose of this study is the docking analysis of five commercially available anti-inflammatory drugs at the binding interface of IL-1 $\beta / \mathrm{IL}-1 \mathrm{R} 1$. The study provides useful information about the binding mechanism of anti-inflammatory compounds thus provides rational to design novel anti-inflammatory agents.

\section{Materials and Methods}

\section{Dataset selection of drug molecules}

For this study, a set of five drug molecules were used (Figure 1) that putatively play a role in inhibiting the IL- $1 \beta$ production and act as antiinflammatory agents. These compounds may also interact with IL- $1 \beta$ protein directly in order to prevent its interaction with its receptor, but their direct mode of interaction is not known. These drugs have been reported by different authors along with their half maximal inhibitory concentration $\left(\mathrm{IC}_{50}\right)$ values [31-34]. The $\mathrm{IC}_{50}$ values of the compounds were reported in different measuring units, thus the values were brought into same "uM" unit and converted into negative log $\left(\mathrm{pIC}_{50}\right)$ values (Table 1 ).

Different molecular databases (PubChem, DrugBank, ChemSpider, UNII, KEGG, ChEBI, ChEMBL) are providing chemical structures of compounds used in this study, however DrugBank database was used to retrieve the chemical structures. Molecules were compiled into a MOE [35] database. Detail of the molecules along with their DrugBank IDs is given in Table 1 and the structures of the compounds are shown in Figure 1.

\section{Protein preparation}

IL- $1 \beta$ is small protein that binds to its compatible receptor protein IL-1RI and is responsible for intra-cell signal cascade [36,37]. Three complex crystal structures of human origin are present in RCSB Brookhaven Protein Data Bank (PDB) with entry codes: 4GAF [38], 1ITB [37] and 4DEP [39] but only 1 ITB represents a pure IL-1 $\beta /$ IL1RI complex. While other structures contains chimera or accessory signalling protein (IL-1R AcP) complexes with IL-1RI. Thus the protein structure of 1ITB was used for this docking study. 1ITB was retrieved from PDB database directly into MOE. The retrieved complex has water molecules, after removing the water molecules, partial charges of the complex were calculated using AMBER 94 force field [40] and energyminimization was performed to release the strain. The protonation state was defined by using 'Protonate 3D' facility provided in MOE. To retain the changes in protein for future use, the final processed complex structure was saved in ".moe" format.

\section{Targeted residues}

The family of IL-1 proteins, which are two agonists (IL-1 $\alpha$, IL$1 \beta$ ) and one antagonist (IL-1ra) exhibits similarity in sequence, gene organization and three-dimensional structure. IL-1 $\alpha$ and IL-1 $\beta$ involves<smiles>C[C@H]1C[C@H]2[C@@H](CCC3=CC(=O)C=C[C@@]32F)[C@@H](O)[C@H](O)C[C@H]1C(=O)CO</smiles>

1<smiles></smiles>

3

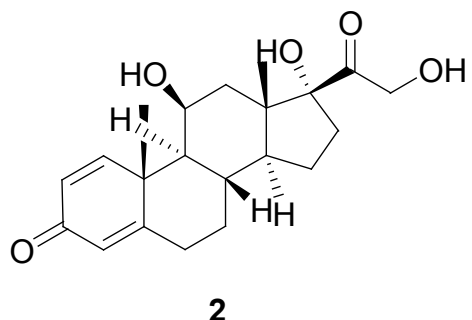<smiles>CN(C)c1ccc(O)c2c1CC1C[C@H]3CC(O)=C(C(N)=O)C(=O)[C@@]3(O)C(O)=C1C2=O</smiles><smiles>CCN(CC)CCCC(C)Nc1ccnc2cc(Cl)ccc12</smiles>

5

Figure 1: Chemical structures of the compounds 1-5 used in this study.

\begin{tabular}{|c|c|c|c|c|c|}
\hline Sr. \# & Compound Name & DrugBank IDs & $\mathrm{plC}_{50}$ & Docking Score & Interacting Residues \\
\hline 1 & Dexamethasone & DB01234 & 8.00 & -3.0883 & $\operatorname{Gln} 15(A), \operatorname{Ser} 13(A), \operatorname{Arg} 11(A), \operatorname{Asp} 12(A)$ \\
\hline 2 & Prednisolone & DB00860 & 6.74 & -3.3257 & Asp12(A), Ser13(A) \\
\hline 3 & Colchicine & DB01394 & 6.60 & -4.5535 & Gln126(A), Lys161(B) \\
\hline 4 & Minocycline & DB01017 & 4.39 & -4.6687 & Lys109(A), Arg163(B) \\
\hline 5 & Chloroquine & DB00608 & 4.12 & -5.129 & Gln15(A), Lys114(B) \\
\hline
\end{tabular}

Table 1: The docking score of Compounds $1-5$ and their interacting residues. The corresponding interacting site is mentioned in hyphen. 


\begin{tabular}{|c|c|c|c|c|c|}
\hline \multirow{9}{*}{ Site A } & IL-1 $\beta$ Residue & IL-1RI Residue & \multirow{9}{*}{ Site B } & IL-1 $\beta$ Residue & IL-1RI Residue \\
\hline & Arg11 & Lys114 & & Ala1 & Tyr261 \\
\hline & Gln14 & Arg163 & & Arg4 & Ser263 \\
\hline & Gln15 & Gly122 & & Glu51 & Lys298 \\
\hline & Lys27 & Glu11 & & Lys93 & Ile250 \\
\hline & Gln32 & Val16 & & Lys94 & Glu252 \\
\hline & Gly33 & Ile110 & & Glu105 & Thr300 \\
\hline & $\mathrm{G} \ln 34$ & Ile14 & & Asn108 & Asn204 \\
\hline & Glu128 & Glu129 & & & \\
\hline
\end{tabular}

Table 2: Interacting residues of Sites A and B of IL-1 $\beta$ with the corresponding residues on IL-1RI.

in similar mode of signal activation by binding the same receptor IL1RI. The receptor binding site of agonists can be subdivided into two sites: site A and site B. Site A of both the agonists shows some of the residues same on each other. Site $B$ exists at an approximate distance of 20-25 $\AA$ from site A. Site-A is different from Site-B in terms of their physiochemical properties of residues and the size of the site, thus Site A can be targeted to increase the specificity of drug interaction with IL- $1 \beta$ [41]. The interacting residues of both sites (A and B) of IL- $1 \beta$ and with their corresponding residues on IL-1RI are tabulated in Table 2.

Three-dimensional structure of IL- $1 \beta$ is surface exposed with planer geometry. Inter-protein interaction analysis of IL-1 $\beta / /$ IL-1RI complex was performed by Chimera [42] delineated almost exact fifteen crucial residues as reported in literature [41-43]. MOE provides an easiness of selecting atoms of desired residues for docking through its ResidueSelector window. The active site was defined for docking by selecting fifteen residues (Table 2) for target oriented docking.

\section{Molecular docking}

MOE program gives moderately fast and correct docking results [44]. It uses a variety of docking algorithms and scoring functions. For the docking, the protein was minimized using the MMFF94 force field (MOE 2013.08), keeping all the heavy atoms fixed until a RMSD gradient of $0.05 \mathrm{kcal}$ mol-1 $\AA-1$ was reached. The active site was generated using MOE residue selector prompt and the defined (15) residues were selected. The docking simulations were performed with default parameters by using Triangle Matcher algorithm in combination London dG as rescoring 1 and GBVI/WSA dG as rescoring 2 methods (MOE 2013.08). The post docking refinement was performed using force field based scoring function. Thirty top ranked docked poses were saved for further study.

\section{Results and Discussion}

\section{Correlation between $\mathrm{pIC}_{50}$ and docking score}

Site A: Initially docking of five compounds were conducted on Site A of IL- $1 \beta$ the correlation was estimated between the score of top ranked docked pose of each compounds with their actual half maximal inhibitory concentration $\left(\mathrm{pIC}_{50}\right)$, that reflected a good correlation with $\mathrm{r}^{2}=0.6668$. However the visual analysis of the interaction of top ranked conformation showed that only three compounds binds with the protein surface. Hence we visualized the mode of interactions of all thirty poses of each compound and selected the best conformation of each compound that showed maximal interaction with the protein. The correlation between the docking score of the best docked pose and the actual inhibitory concentration improved drastically with $\mathrm{r}^{2}=0.7570$. The correlation plot is shown in Figure 2.

Site B: To detect the role of site B, the compounds were also docked at site B of IL- $1 \beta$, however the relationship between the top ranked docked conformation of each compound and the experimental $\mathrm{pIC}_{50}$ was found to be weak with $\mathrm{r}^{2}=0.5606$. The interaction analysis also reflected that compounds do not bind significantly with site B. The conformational sampling also confirmed that the compounds do not significantly interact with site $B$, hence suggested that these compounds target site A of the IL- $1 \beta$ protein and inhibit IL-1 $\beta /$ IL-1RI interface at site A.

\section{Docking results}

Visual analysis of the interaction between the ligands the protein was performed in Chimera. Chimera gives an easy handling to analyse the interactions. The selected conformations were exported into mol2 files and opened in Chimera. The modes of interactions of all five compounds are displayed in Figures 3 and 4.

\section{Binding mode of Compound 1}

Compound 1 has several active moieties for binding with protein, thus it showed good interactions with three residues at the interface. The methanol present at the cyclo-hexanol ring of the compound mediates $\mathrm{H}$-bond with the carbonyl moiety of the main chain of Ser13(A) at a distance of $2.439 \AA$. The Hydroxyl group of compound 1 mediates bidentate interaction with $\operatorname{Arg} 11(\mathrm{~A})$ and $\mathrm{Asp} 12(\mathrm{~A})$ at a distance of 2.847 $\AA$ and $1.893 \AA$, respectively.

Moreover the side chain amino group of $G \ln 15(A)$ interacts with the hydroxyl moiety of the ligand at a distance of $2.762 \AA$ (Figure $3 a)$. The docking mode of compound 1 revealed that the compound significantly interact with the site A of IL- $1 \beta$ protein.

\section{Binding mode of Compound 2}

Compound 2 is a steroid in nature as of Compound 1 and contains the similar moieties to interact with the protein. Similar to the mode of interaction of compound 1 , the methanol moiety at the cyclohexane ring of compound 2 also interacted with the main chain carbonyl group of Ser13(A) at a distance of $2.044 \AA$. The main chain carbonyl group of Asp12(A)mediates H-bond with the hydroxyl moiety of the compound 2 at a distance of $2.295 \AA$. The docking orientation of compound 2 is presented in Figure $3 b$.

\section{Binding mode of Compound 3}

The binding mode analysis of compound 3 showed that this compound forms three possible binding interactions with two surrounding residues. The oxygen of $\mathrm{N}$-methylacetamide moiety present at the second ring cycloheptane of the ligand, mediates a week interaction with amino group of $\operatorname{Gln} 126(\mathrm{~A})$ at a distance measurement of $3.013 \AA$. The main chain amino group of the Lys161(B) formed bidentate interaction with two different oxygen moieties present on the ligand with the distance of $1.966 \AA$ and $1.448 \AA$, respectively (Figure 3c).

\section{Binding mode of Compound 4}

Compound 4 constitutes four rings in main structure thus labelled with numeric in order to mention the position of interacting moieties present on the compound. The docked mode of the compound 4 showed 

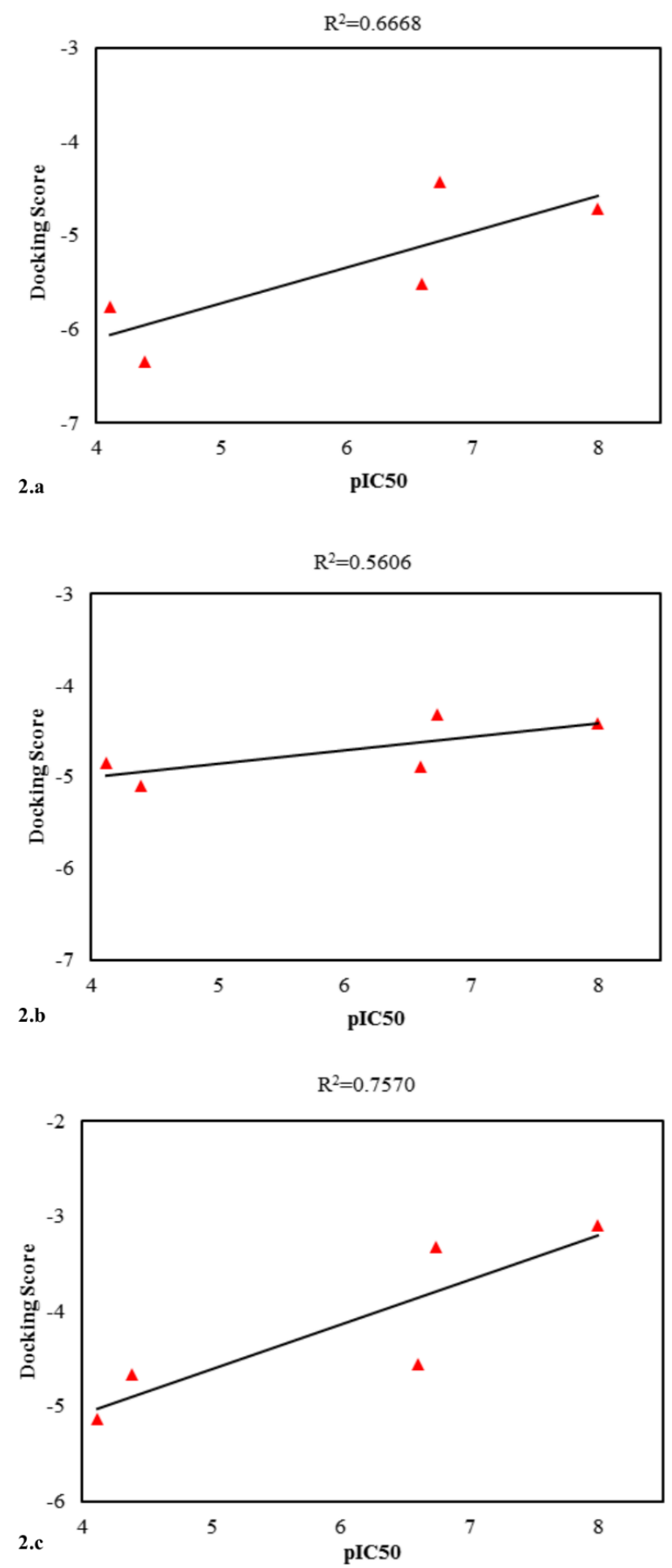

Figure 2: Correlation plot between the $\mathrm{plC}_{50}$ values and the Docking Score of the compounds. a) Correlation between the top ranked docked poses of compounds 1-5 and the $\mathrm{plC}_{50}$ values at the site $\mathrm{A}$ of the protein complex. $\mathbf{b}$ ) Correlation between the top ranked docked poses of compounds 1-5 and the $\mathrm{pIC}$ values at the site $\mathrm{B}$ of the protein complex c) Correlation between the

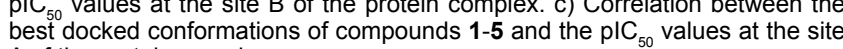
A of the protein complex.

that the compound mediates several interactions with the surrounding residues at the IL-1 $\beta / \mathrm{IL}-1 \mathrm{RI}$ interface. Hydroxyl and carbonyl groups

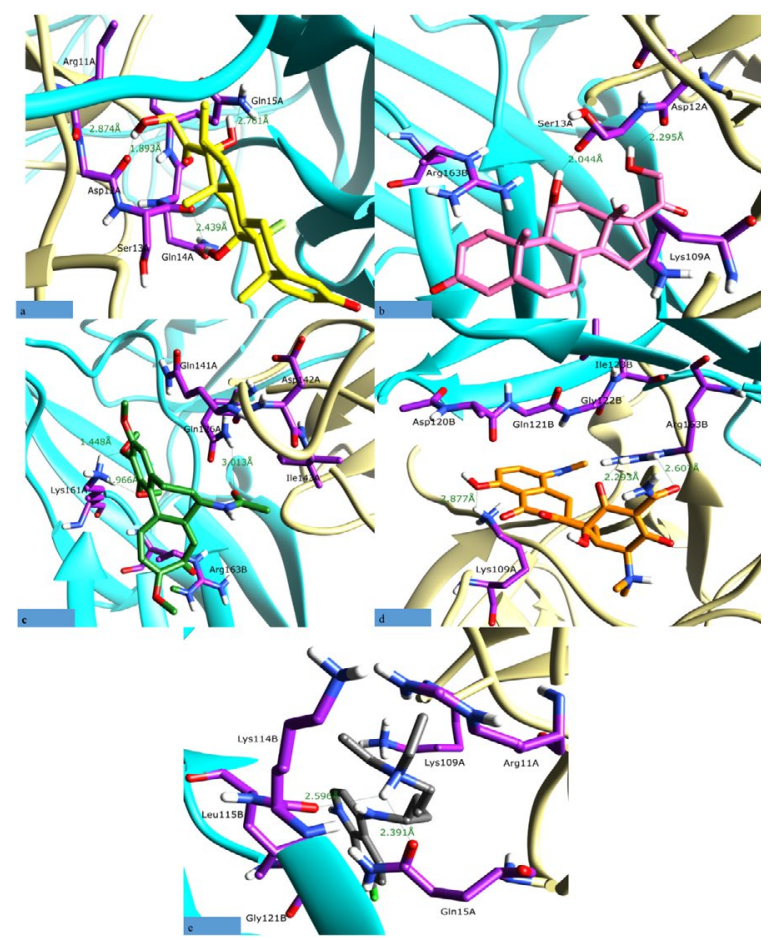

Figure 3: The binding modes of Compounds 1(a), 2(b), 3(c), 4(d) and 5(e) at the IL-1ß/IL-1RI complex interface.

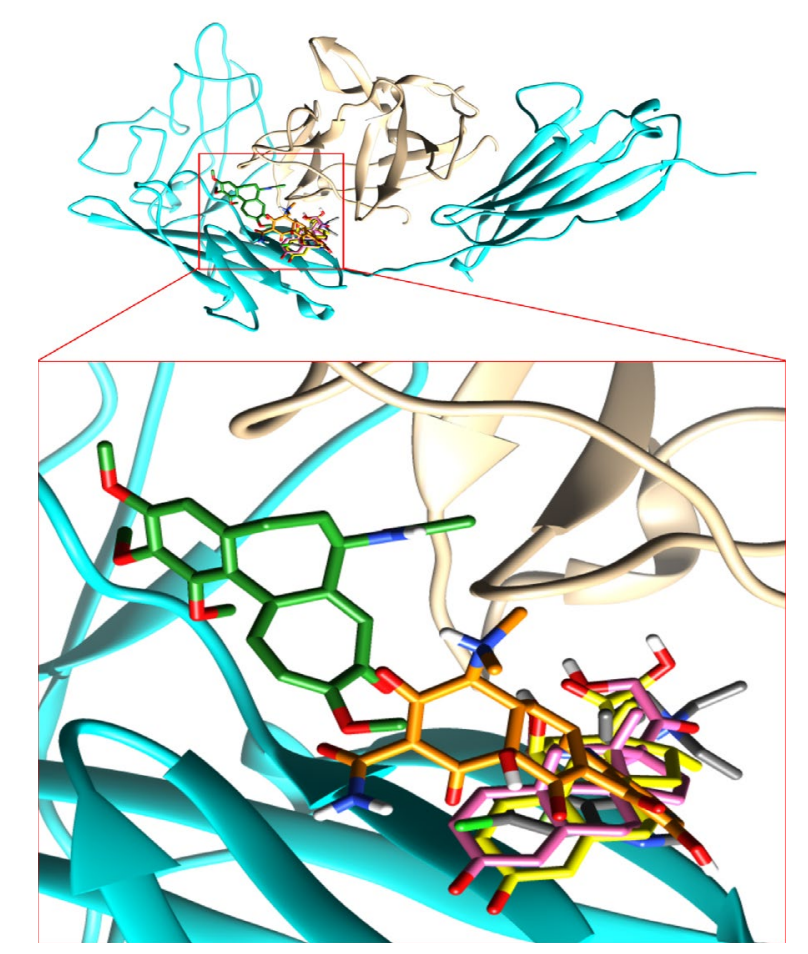

Figure 4: Enhanced view of the cluster of all compounds at the site $A$ of the $\mathrm{IL}-1 \beta$.

weekly interacted with main chain amide group of Lys109(A) at a distance of $2.877 \AA$. The amide group of Arg163(B) mediates two $\mathrm{H}$-bonds with the hydroxyl moieties present at ring 4 with distance of $2.293 \AA$ and $2.607 \AA$, respectively (Figure 3d). 


\section{Binding mode of Compound 5}

The docked conformation of compound 5 showed that the N-ethyl$\mathrm{N}$-methylethanamine moiety of compound mediates bi-dentate interaction. The compound interacted with side chain of $\mathrm{Gln} 15(\mathrm{~A})$ and main chain carbonyl moiety of Lys114(B) at a distance of $2.391 \AA$ and $2.596 \AA$, respectively (Figure $3 \mathrm{e}$ ).

An excellent correlation was obtained between the docking score the experimental $\mathrm{IC}_{50}$ values when the docking was conducted at site A of IL- $1 \beta$. The docking results reflected that significant binding interactions are present between protein-ligand complexes. This study opens new horizon to design and develop novel anti-inflammatory compounds that targets IL- $1 \beta$ and specifically inhibits IL-1 $\beta /$ IL-1RI interaction thus stops inflammatory cascade.

\section{Conclusion}

Molecular docking helps in understanding the possible interaction between protein and the ligand. The study was conducted with the aim to get insights of the possible direct binding behaviours of commercially available anti-inflammatory drugs that leads to decrease the effect of IL$1 \beta$ and to detect the potential binding site on the interface of IL-1 $\beta /$ IL-1R1 complexes that can be used to target IL-1 $\beta$. A good correlation value of docking results at site-A, makes it more attracting rather than the site- $\mathrm{B}$. At site A, more conformations showed interactions with IL$1 \beta$ chain rather than IL-1R1 chain. While at site $B$, more conformations showed interaction with IL-1R1 chain rather than IL- $1 \beta$ chain. Thus it can be inferred that the Site A contains amino acids crucial for binding and blockage of IL-1 $/$ IL-1R1 interaction and by targeting these residues, more specific IL- $1 \beta$ inhibitors can be designed by using computational drug design strategy. The findings of this study will help in providing preliminary information for structure based drug discovery against IL- $1 \beta$.

\section{References}

1. Dinarello CA (2011) Interleukin-1 in the pathogenesis and treatment of inflammatory diseases. Blood 117: 3720-3732.

2. Sims JE, Smith DE (2010) The IL-1 family: regulators of immunity. Nat Rev Immunol 10: 89-102

3. Lichtman AH, Chin J, Schmidt JA, Abbas AK (1988) Role of interleukin 1 in the activation of T lymphocytes. Proc Natl Acad Sci USA 85: 9699-9703.

4. Dinarello CA (1998) Interleukin-1, interleukin-1 receptors and interleukin-1 receptor antagonist. Int Rev Immunol 16: 457-499.

5. Dinarello CA (2009) Immunological and inflammatory functions of the interleukin-1 family. Annu Rev Immunol 27: 519-550.

6. Dinarello CA (2010) Anti-inflammatory Agents: Present and Future. Cell 140: 935-950.

7. Dinarello CA, Simon A, van der Meer JW (2012) Treating inflammation by blocking interleukin-1 in a broad spectrum of diseases. Nat Rev Drug Discov 11: 633-652

8. Gabay C, Lamacchia C, Palmer G (2010) IL-1 pathways in inflammation and human diseases. Nat Rev Rheumatol 6: 232-241.

9. Garlanda C, Dinarello CA, Mantovani A (2013) The interleukin-1 family: back to the future. Immunity 39: 1003-1018.

10. Dinarello CA (1997) Induction of interleukin-1 and interleukin-1 receptor antagonist. Semin Oncol 24: 81-93.

11. Dinarello CA (1997) Interleukin-1. Cytokine Growth Factor Rev 8: 253-265

12. Braddock M, Quinn A (2004) Targeting IL-1 in inflammatory disease: new opportunities for therapeutic intervention. Nat Rev Drug Disc 3: 330-340.

13. Liu T, Jiang CY, Fujita T, Luo SW, Kumamoto E (2013) Enhancement by interleukin- $1 \hat{~}^{2}$ of AMPA and NMDA receptor-mediated currents in adult rat spinal superficial dorsal horn neurons. Mol Pain 9: 16.
14. Gustafson-Vickers SL, Lu VB, Lai AY, Todd KG, Ballanyi K, et al. (2008) Long-term actions of interleukin-1beta on delay and tonic firing neurons in rat superficial dorsal horn and their relevance to central sensitization. Mol Pain 4: 63.

15. Krelin Y, Voronov E, Dotan S, Elkabets M, Reich E, et al. (2007) Interleukin1 beta-driven inflammation promotes the development and invasiveness of chemical carcinogen-induced tumors. Cancer Res 67: 1062-1071.

16. Carmi Y, Dotan S, Rider P, Kaplanov I, White MR, et al. (2013) The role of IL-1 $\hat{I}^{2}$ in the early tumor cell-induced angiogenic response. J Immunol 190: 35003509 .

17. Mantovani A (2009) Cancer: Inflaming metastasis. Nature 457: 36-37.

18. Dinarello CA (2002) The IL-1 family and inflammatory diseases. Clin Exp Rheumatol 20: S1-S13.

19. Tack CJ, Stienstra R, Joosten LA, Netea MG (2012) Inflammation links excess fat to insulin resistance: the role of the interleukin-1 family. Immunol Rev 249 : 239-252.

20. Freigang S, Ampenberger F, Weiss A, Kanneganti TD, Iwakura Y, et al. (2013) Fatty acid-induced mitochondrial uncoupling elicits inflammasome-independent IL-1 $1 \pm$ and sterile vascular inflammation in atherosclerosis. Nat Immunol 14 1045-1053.

21. Gao D, Madi M, Ding C, Fok M, Steele T, et al. (2014) Interleukin-1ß mediates macrophage-induced impairment of insulin signaling in human primary adipocytes. Amer J Physiol Endocrinol Met 307: E289-E304.

22. Ehses JA, Lacraz G, Giroix MH, Schmidlin F, Coulaud J, et al. (2009) IL-1 antagonism reduces hyperglycemia and tissue inflammation in the type 2 diabetic GK rat. Proc Natl Acad Sci USA 106: 13998-14003.

23. McGillicuddy FC, Harford KA, Reynolds CM, Oliver E, Claessens M, et al. (2011) Lack of interleukin-1 receptor I (IL-1RI) protects mice from high-fat diet-induced adipose tissue inflammation coincident with improved glucose homeostasis. Diabetes 60: 1688-1698.

24. Owyang AM, Maedler K, Gross L, Yin J, Esposito L, et al. (2010) XOMA 052, an anti-IL-1\{beta\} monoclonal antibody, improves glucose control and \{beta\}-cell function in the diet-induced obesity mouse model. Endocrinology 151: 25152527.

25. Sauter NS, Schulthess FT, Galasso R, Castellani LW, Maedler K (2008) The antiinflammatory cytokine interleukin-1 receptor antagonist protects from highfat diet-induced hyperglycemia. Endocrinol 149: 2208-2218.

26. Dhimolea E (2010) Canakinumab. MAbs 2: 3-13.

27. Cignarella A (2011) Targeting interleukin-1 $\tilde{A} \ddot{Y}$ hampers atherosclerosis progression - is there great promise? Atherosclerosis 217: 64-66.

28. Wu C, Ying H, Bose S, Miller R, Medina L, et al. (2009) Molecular construction and optimization of anti-human IL-1alpha/beta dual variable domain immunoglobulin (DVD-lg) molecules. MAbs 1: 339-347.

29. Halim SA, Jawad M, llyas M, Mir Z, Mirza AA, et al. (2015) In silico identification of novel IL-1 $\hat{\mid}^{2}$ inhibitors to target protein-protein interfaces. Comput Biol Chem 58: 158-166.

30. Kern JA, Lamb RJ, Reed JC, Daniele RP, Nowell PC (1988) Dexamethasone inhibition of interleukin 1 beta production by human monocytes. Posttranscriptional mechanisms. J Clin Invest 81: 237-244.

31. Ben-Chetrit E, Bergmann S, Sood R (2006) Mechanism of the anti-inflammatory effect of colchicine in rheumatic diseases: a possible new outlook through microarray analysis. Rheumatology 45: 274-282.

32. Bondeson J, Sundler R (1995) Auranofin inhibits the induction of interleukin 1 beta and tumor necrosis factor alpha mRNA in macrophages. Biochem Pharmacol 50: 1753-1759.

33. Pang T, Wang J, Benicky J, Saavedra JM (2012) Minocycline ameliorates LPS induced inflammation in human monocytes by novel mechanisms including LOX-, Nur77 and LITAF inhibition. Biochim Biophys Acta 1820: 503-510.

34. Rordorf-Adam C, Lazdins J, Woods-Cook K, Alteri E, Henn R, et al. (1989) An assay for the detection of interleukin-1 synthesis inhibitors: effects of antirheumatic drugs. Drugs Exp Clin Res 15: 355-362.

35. Molecular Operating Environment (MOE) (2014) Chemical Computing Group Inc., 1010 Sherbooke St. West, Suite \#910, Montreal, QC, Canada, H3A 2R7.

36. Wang D, Zhang S, Li L, Liu X, Mei K, et al. (2010) Structural insights into the assembly and activation of IL-1 $\hat{I}^{2}$ with its receptors. Nat Immunol 11: 905-911. 
Citation: Halim SA, Jawad M (2015) Attempt to Explore the Binding Mechanism of IL-1 $\beta$ Inhibitors via Molecular Docking Studies. Med chem 5: 452457. doi:10.4172/2161-0444.1000300

37. Vigers GP, Anderson LJ, Caffes P, Brandhuber BJ (1997) Crystal structure of the type-I interleukin-1 receptor complexed with interleukin-1beta. Nature 386 : 190-194.

38. Hou J, Townson SA, Kovalchin JT, Masci A, Kiner O, et al. (2013) Design of a superior cytokine antagonist for topical ophthalmic use. Proc Natl Acad Sci USA 110: 3913-3918.

39. Thomas C, Bazan JF, Garcia KC (2012) Structure of the activating IL-1 receptor signaling complex. Nat Struct Mol Biol 19: 455-457.

40. Darian E, Gannett PM (2005) Application of molecular dynamics simulations to spin-labeled oligonucleotides. J Biomol Struct Dyn 22: 579-593.

41. Evans RJ, Bray J, Childs JD, Vigers GP, Brandhuber BJ, et al. (1995) Mapping receptor binding sites in interleukin (IL)-1 receptor antagonist and IL-1 beta by site-directed mutagenesis. Identification of a single site in IL-1ra and two sites in IL-1 beta. J Biol Chem 270: 11477-11483.

42. Pettersen EF, Goddard TD, Huang CC, Couch GS, Greenblatt DM, et al. (2004) UCSF Chimera--a visualization system for exploratory research and analysis. $J$ Comput Chem 25: 1605-1612.

43. Vigers GP, Dripps DJ, Edwards CK 3rd, Brandhuber BJ (2000) X-ray crysta structure of a small antagonist peptide bound to interleukin-1 receptor type $1 . J$ Biol Chem 275: 36927-36933.

44. Warren GL, Andrews CW, Capelli AM, Clarke B, LaLonde J, et al. (2006) A critical assessment of docking programs and scoring functions. J Med Chem 49: 5912-5931. 